\title{
DIRECTIONAL ASYMMETRY IN HANDEDNESS AND HAND EFFICIENCY
}

\author{
Idenya PM, Gichangi P, Ogeng'o J
}

Correspondence to Dr. Pamela Mandela Idenya, MBChB, MMed, MPH, Senior Lecturer, University of Nairobi, School of Medicine, Department of Human Anatomy, Chiromo Campus, P. O. Box 1967600202, KNH, Nairobi Kenya. Email: pamela.idenya@uonbi.ac.ke Mobile: +254(0)733619815

\begin{abstract}
Several studies analyse anthropometric dimensions of the hands, but few look at how they influence hand performance or hand efficiency. In this analytic cross-sectional study conducted amongst 162 preclinical medical students, directional asymmetry was evaluated in relation to hand preference and hand efficiency in order to determine whether it can be used as an indicator for outcomes of hand dominance. Directional asymmetry (DA) was established by calculating differences in the mean hand measurements and the mean hand volumes. Hand preference was assessed using the modified Edinburgh Handedness Inventory, and handedness categories determined by applying the Geschwind Score. Hand dominance was categorized from the laterality score obtained from differences between left and right hands. Differences in hand dimensions were evaluated in relation to hand preference and hand efficiency. An apparent similarity in the morphology of the hands was suggested by the highly positive statistically significant result in the paired samples correlation test across all the parameters $(p<0.001)$. A positive association (not statistically significant) was noted between the handedness categories and the demonstrated directional asymmetry. No gender disparity was found in the relationship between DA and Hand efficiency by grip strength testing. The EHI-GS hand preference category positively indicated the preferred hand but did not on its own designate hand dominance or hand proficiency. Notwithstanding the gender, EHI-GS handedness neither predicted DA nor hand efficiency. Similarly, neither EHI-GS hand preference nor hand efficiency by grip strength testing could predict DA in males and females alike.
\end{abstract}

Key words: Hand performance, Hand proficiency, Hand dominance, Grip strength testing, Laterality

\section{INTRODUCTION}

Handedness in humans is considered a classic example of directional asymmetry, with the majority being categorized as right-handed and the tendency to show a greater development of the long bones in the right arms. Although several studies have analysed anthropometric dimensions of the hands, few have looked at these dimensions in relation to other hand function parameters. For example, Srhoj et al. (2002) and Cavala et al. (2008) evaluated the morphological characteristics of handball players including hand length and width. Barut et al. (2008) evaluated hand dimensions in basketball, volleyball and handball players while Buffa et al. (2007) evaluated palmar length and finger lengths. However, few of these studies examine any relationships between the hand dimensions and hand performance or between the hand dimensions and hand efficiency.

There is a general assumption that a direct association exists between morphological asymmetry and behaviour. Some researchers have argued that this can happen through mechanically driven bone growth and remodelling. After assessing skeletal indicators for handedness in humans, Steele (2000) proposed that skeletal bilateral directional asymmetries (DAs) may be used as indicators of the influence of the mechanical environment on bone structure. In another study, Mayor et al. (1976) found direction of asymmetry to be individually characteristic of the majority of 
individuals, irrespective of their hand preference. As for Lazenby (2008), he concluded that directional asymmetry (DA) is a characteristic that superimposes an underlying and etiologically distinct fluctuating asymmetry (FA), which in turn may either moderate or exaggerate DA in any given individual.

Other researchers describe greatly increased asymmetry between the playing and nonplaying arms of racquetball and tennis athletes. The description by Jones et al. (1977) of a highly significant hypertrophy of bone in response to exercise in a group of professional tennis players exemplifies the influence that the mechanical environment can have on bone structure. As Kontuulainen et al. (2001, 2002) explained, the structural adaptation of the humeral shaft to long-term loading is achieved through periosteal enlargement of the bone cortex. Their argument being that exerciseinduced bone gain can be well maintained with decreased activity; but, maintenance of the bone gain is independent of the age at which the said activity was started.

Some studies have showed that functional handedness leads to both periosteal and endosteal expansion of the second metacarpal cortex on the dominant side, with a resultant increase in bone strength without necessarily an increase in cortical thickness. This could account for the significant right-hand bias which is observed for measures of structural strength in mid-shaft geometry. In effect, these factors contribute to differences in digit sizes and hence DA in the hands. Lazenby et al. (2008) recorded a right-hand bias only with regard to mediolateral, and not dorso-palmar dimensions, thereby exhibiting a directional asymmetry in hand breadth at the distal palmar arch. Their results confirm and extend previous research which has documented structural asymmetries and limb dominance, which can then be assessed in relation to handedness.

Although Malina and Buschang (1984) suggested that adults have more pronounced asymmetries in favour of the right side even when handedness has been controlled for, lefthanded individuals in the "normal" population have been shown to have equivalent but reversed asymmetry in hand dimensions as compared to right-handed individuals. Steele 2000) reported that left-handed individuals are also likely to have stronger grip in either hand than the right-handed individuals. It is noteworthy that this pattern of asymmetry has been reported in both left-handers and righthanders.

The question arises then as to whether anatomical asymmetry would influence hand efficiency. The current study evaluated directional asymmetry was in relation to hand preference and hand dominance amongst 162 randomly selected preclinical medical students, in order to determine whether DA could be used as an indicator for other hand parameters.

\section{METHODOLOGY}

\section{Measuring directional asymmetry}

With ethical approval from the UONKNH - ERC and signed informed consent obtained, both left- and right-hand measurements were taken from 162 preclinical students (94 females and 68 males were randomly selected from a finite population of 900 preclinical students) using an Epson ${ }^{\circledR}$ L220 scanner photocopier. The hand was positioned on the palmar side with the digits fully extended on a flat, hard surface and adducting from the second to the fifth digit while extending the thumb slightly. For each scanned hand, hand width, hand length, third digit length, and palmar length were measured (Pheasant, 1990). The degree of asymmetry was determined by subtracting the values for the right hand from those of the left, with any value other than " 0 " taken to indicate hand asymmetry (Tomkinson et al., 2003; Kulaksiz and Gozil, 2002). If the value was positive, the asymmetry was recorded to favour the right hand, while a negative value indicated asymmetry in favour of the left hand.

Hand size and hand volume were estimated by geometric calculations from the mean scanned hand anthropometric measurements. Each component of the hand was treated as a cylinder, whose volume was then calculated using this formula: $V_{\text {digit }}=\pi r 2 h$, where $\pi=$ 
3.14, $r=$ width of finger $/ 2, h=$ length of finger. $\mathrm{V}_{\text {palm }}=\pi r 2 h$, where $r=$ Palm Circumference $/ 2 \pi$. Vhand $=V_{\text {all digits }}+V_{\text {palm. }}$. The end results included hand volumes from selfreported hand measurements and hand volumes from scanned hand measurements.

The data was analyzed for differences between the calculated hand volumes and tested for variance using one-way ANOVA. Directional asymmetry (DA) was determined by calculating the differences in the mean hand measurements and the calculated mean hand volumes.

\section{Measuring handedness}

Hand preference was assessed using the modified Edinburgh Handedness Inventory (Oldfield 1971), which applies 10 items pertaining to hand-preference in writing, drawing, throwing a ball, use of scissors, use of toothbrush, use of knife (without fork), use of spoon, use of broom (upper hand), striking a match, and opening a box. The items were checked off using the options 'always (left/right)', 'usually (left/right)' and 'no preference'. The EHI Laterality Index was calculated for each participant by counting the total number of checks (Left and Right) for each item as follows: $\mathrm{R}=(\mathrm{RH}-\mathrm{LH} / \mathrm{RH}+\mathrm{LH}) \times$ 100 . This resulted in LI scores ranging from 100 to +100 , where the handedness categories included Left-Handed ( $R \leq-40)$, ambidextrous
$(-40<\mathrm{R}<+40)$ and Right-Handed $(\mathrm{R} \geq+40)$. To calculate the Geschwind Score Laterality Quotient, each check was multiplied by a factor based on a Likert Scale where always left hand $=-5$, usually left hand $=-2.5$, no preference $=$ 0 , usually right $=2.5$ and always right $=5$. Each check was separately scaled and the totals used to give GS LQ = (GS RH - GS LH/ GS RH + GS LH)*100. The LQ score range was from -100 to +100 . These were interpreted as Edinburgh Handedness Inventory Geschwind Score (EHI GS) hand preference categories of Left-Handed (GS $\leq-100)$, Ambidextrous ( -100 $<\mathrm{GS}<+100)$ and Right-Handed (GS $\geq+100)$.

\section{Determining Hand efficiency}

Hand efficiency was determined by testing for grip strength using the Jamar Dynamometer $\AA$. Grip strength measurements were obtained by requesting the participant to gradually increase and maintain their maximum grip force exertion for a brief time and repeating the cycle after a brief break. The mean of three trials was considered a more accurate measure of hand strength for a particular hand. The maximal grip strength (kgs) was obtained and differences between the two hands ( $\mathrm{RH}-\mathrm{LH})$ was used to calculate a laterality score by which the participants were categorized as right-hand dominant (value $>0$ ), left-hand dominant (value $<0$ ) or no-hand dominant (value $=0$ ).

\section{RESULTS}

\section{Directional asymmetry in different hand dimensions}

The hand anthropometric measurements show a general asymmetry in favour of the right side (rtDA), as confirmed by the positive t-values obtained for all dimensions measured (Table 1 ). Of note is the highly positive statistically significant paired samples correlation test results across all measured parameters ( $p<$ 0.001 ), which suggests the apparent similarity in the morphology of the right and left hands.

The paired samples T-test did not reveal statistically significant differences between the right and the left hands for measurements of palm length ( $p=0.282)$, thumb length ( $p=$ $0.059)$, thumb width $(p=0.680)$, middle finger length $(p=0.290)$, middle finger width $(p=$ $0.164)$, and ring finger length $(p=0.175)$. However, the paired samples $\mathrm{T}$-test recorded statistically significant differences between the right and left hands for measurements of hand length $(p=0.017)$, hand width $(p<0.001)$, palm breadth $(p<0.001)$, index finger length $(p=0.011)$, index finger width $(p<0.001)$, ring finger width $(p<0.001)$, little finger length $(p=0.011)$, little finger width $(p=$ 0.031 ) and calculated hand volume ( $p<$ 0.001). 
Table1: Paired Samples Statistics for Hand Measurements

\begin{tabular}{|c|c|c|c|c|c|}
\hline Pairs & Dimensions & Mean \pm SD & Correl. (Sig.) & Mean Diff. \pm SD & $\begin{array}{l}\mathrm{T} \text { (Sig. 2- } \\
\text { tailed) }\end{array}$ \\
\hline \multirow{2}{*}{1} & Rt Hand Length & $185.81 \pm 11.54$ & \multirow{2}{*}{$0.966(0.000)$} & \multirow{2}{*}{$0.58 \pm 3.08$} & \multirow{2}{*}{$\begin{array}{l}2.401 \\
\left(0.017^{*}\right)\end{array}$} \\
\hline & Lt Hand Length & $185.23 \pm 11.93$ & & & \\
\hline \multirow{2}{*}{2} & Rt Hand Width & $70.53 \pm 6.12$ & \multirow{2}{*}{$0.873(0.000)$} & \multirow{2}{*}{$1.26 \pm 3.31$} & \multirow{2}{*}{$\begin{array}{l}4.835 \\
(0.000 *)\end{array}$} \\
\hline & Lt Hand Width & $69.27 \pm 6.78$ & & & \\
\hline \multirow{2}{*}{3} & Rt Palm Length & $105.45 \pm 7.18$ & \multirow{2}{*}{$0.920(0.000)$} & \multirow{2}{*}{$0.25 \pm 2.91$} & \multirow{2}{*}{$1.080(0.282)$} \\
\hline & Lt Palm Length & $105.20 \pm 7.37$ & & & \\
\hline \multirow{2}{*}{4} & Rt Palm Breadth & $81.20 \pm 6.16$ & \multirow{2}{*}{$0.942(0.000)$} & \multirow{2}{*}{$1.32 \pm 2.11$} & \multirow{2}{*}{$\begin{array}{l}7.977 \\
(0.000 *)\end{array}$} \\
\hline & Lt Palm Breadth & $79.88 \pm 6.26$ & & & \\
\hline \multirow{2}{*}{5} & Rt Thumb Length & $63.70 \pm 5.40$ & \multirow{2}{*}{$0.814(0.000)$} & \multirow{2}{*}{$0.51 \pm 3.38$} & \multirow{2}{*}{$1.904(0.059)$} \\
\hline & Lt Thumb Length & $63.20 \pm 5.66$ & & & \\
\hline \multirow{2}{*}{6} & Rt Thumb Width & $18.31 \pm 2.02$ & \multirow{2}{*}{$0.742(0.000)$} & \multirow{2}{*}{$0.05 \pm 1.52$} & \multirow{2}{*}{$0.413(0.680)$} \\
\hline & Lt Thumb Width & $18.26 \pm 2.20$ & & & \\
\hline \multirow{2}{*}{7} & Rt Index Finger Length & $70.62 \pm 4.91$ & \multirow{2}{*}{$0.903(0.000)$} & \multirow{2}{*}{$0.44 \pm 2.18$} & \multirow{2}{*}{$\begin{array}{l}2.558 \\
\left(0.011^{*}\right)\end{array}$} \\
\hline & Lt Index Finger Length & $70.18 \pm 4.98$ & & & \\
\hline \multirow{2}{*}{8} & Rt Index Finger Width & $16.99 \pm 1.71$ & \multirow{2}{*}{$0.796(0.000)$} & \multirow{2}{*}{$0.35 \pm 1.09$} & 4.022 \\
\hline & Lt Index Finger Width & $16.64 \pm 1.72$ & & & $(0.000 *)$ \\
\hline 0 & Rt Middle Finger Length & $80.27 \pm 5.32$ & (0م0) & 70 & (10020 \\
\hline 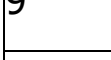 & Lt Middle Finger Length & $80.13 \pm 5.47$ & $0.951(0.000)$ & 0.1 & $0.290)$ \\
\hline 10 & Rt Middle Finger Width & $16.40 \pm 1.77$ & (חمח ח) כ 800 & $012+112$ & $1398(0164)$ \\
\hline 10 & Lt Middle Finger Width & $16.27 \pm 1.80$ & $0.00<(0.000)$ & 0.12 & $1.090(0.104)$ \\
\hline 11 & Rt Ring Finger Length & $74.37 \pm 5.42$ & 0 ०46 ( $0 \cap 00)$ & $010+170$ & 1362 \\
\hline 11 & Lt Ring Finger Length & $80.13 \pm 5.47$ & $0.940(0.000)$ & $0.19 \pm 1.19$ & $1.00<(0.1 / 0)$ \\
\hline 12 & Rt Ring Finger Width & $15.87 \pm 1.66$ & 0001 & & 4.604 \\
\hline 12 & Lt Ring Finger Width & $15.44 \pm 1.73$ & 0.12 & 1.19 & $(0.000 *)$ \\
\hline 13 & Rt Little Finger Length & $59.27 \pm 5.04$ & & & 2.563 \\
\hline 13 & Lt Little Finger Length & $58.85 \pm 5.14$ & $.000)$ & .08 & $\left(0.011^{*}\right)$ \\
\hline 14 & Rt Little Finger Width & $14.38 \pm 1.56$ & & & 2.180 \\
\hline 14 & Lt Little Finger Width & $14.20 \pm 1.49$ & $0.105(0.000)$ & 04 & $(0.031 *)$ \\
\hline 15 & Rt Hand Volume & $\begin{array}{r}393.11 \pm \\
101.25 \\
\end{array}$ & & & 4.366 \\
\hline & Lt Hand Volume & $\begin{array}{r}381.60 \pm \\
102.52\end{array}$ & 0. & 3.34 & $(0.000 *)$ \\
\hline
\end{tabular}

$\mathrm{N}=162$

Relationship of directional asymmetry and EHIGS hand preference category

Further analysis of the resultant directional asymmetry subgrouping was done with respect to EHI-GS hand preference categories by cross-tabulation of the variables (Table 2).

The results indicate that of the 14 EHI-GS ambidextrous subjects, there were 3 (21.4\% in EHI-GS handedness category) with left-sided 
DA and 11 (78.6\% in EHI-GS handedness category) with right-sided DA. Of the 7 EHI-GS left-handed subjects, $4(57.1 \%$ in EHI-GS handedness category) had left-sided DA and 3 (42.9\% in EHI-GS handedness category) had right-sided DA. In the EHI-GS right-handed category, there were $39(27.7 \%$ in EHI-GS handedness category) with left-sided DA, 98 (69.5\% in EHI-GS handedness category) with right-sided DA and $4(2.8 \%$ in EHI-GS handedness category) with no DA. The 4 who showed no-favoured sidedness in directional asymmetry represented $2.5 \%$ of the total study population.
In order to determine the level of association between EHI GS Handedness Category and the resultant directional asymmetry, we subjected the results to the Pearson Chi Square test of association. This gave the total population $\mathrm{X}_{2}=$ 3.781 ( $p=0.436$ @ 95\% CI), which denotes that there was a positive association between the handedness categories and the demonstrated directional asymmetry; but this association was not statistically significant. In essence, while the EHI-GS hand preference category can positively indicate the preferred hand, it does not on its own designate the dominant or more efficient hand.

Table 2: Cross-tabulation of Directional Asymmetry Subgroups with EHI-GS Hand Preference Categories

\begin{tabular}{|c|c|c|c|c|c|}
\hline \multicolumn{2}{|c|}{} & \multicolumn{2}{c|}{ Directional Asymmetry Subgroup } & Total \\
\hline \multirow{4}{*}{$\begin{array}{c}\text { EHI-GS } \\
\text { Hand } \\
\text { Preference }\end{array}$} & Category & Left DA & None & Right DA & \\
\cline { 2 - 6 } & Left-Handed & $4(8.7 \%)$ & $0(0.0 \%)$ & $3(2.7 \%)$ & $7(4.3 \%)$ \\
\cline { 2 - 6 } & Ambidextrous & $3(6.5 \%)$ & $0(0.0 \%)$ & $11(9.8 \%)$ & $14(8.6 \%)$ \\
\cline { 2 - 6 } & Right-Handed & $39(84.8 \%)$ & $4(100 \%)$ & $98(87.5 \%)$ & $141(87.0 \%)$ \\
\cline { 2 - 6 } & Total (\% of Total) & $46(28.4 \%)$ & $4(2.5 \%)$ & $112(69.1 \%)$ & $162(100 \%)$ \\
\hline
\end{tabular}

$* \%$ is within the directional asymmetry subgroup

Table 3: Cross-tabulation of Directional Asymmetry Subgroups with EHI-GS Hand Preference Categories Distributed by Gender

\begin{tabular}{|c|c|c|c|c|c|}
\hline & \multicolumn{4}{|c|}{ Directional Asymmetry Subgroup } \\
\hline Gender & $\begin{array}{l}\text { EHI-GS Hand Preference } \\
\text { Category }\end{array}$ & Left DA & None & Right DA & Total \\
\hline \multirow{4}{*}{ 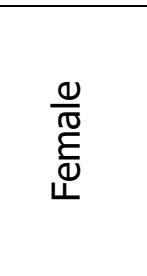 } & Left-Handed & $3(11.1 \%)$ & 0 & $1(1.5 \%)$ & $4(4.3 \%)$ \\
\hline & Ambidextrous & $1(3.7 \%)$ & 0 & $6(9.2 \%)$ & $7(7.4 \%)$ \\
\hline & Right-Handed & $23(85.2 \%)$ & $2(100 \%)$ & $58(89.2 \%)$ & $83(88.3 \%)$ \\
\hline & $\begin{array}{l}\text { Total (\% of Total } \\
\text { Females) }\end{array}$ & $\begin{array}{c}27 \\
(28.7 \%)\end{array}$ & $\begin{array}{c}2 \\
(2.1 \%)\end{array}$ & $\begin{array}{c}65 \\
(69.1 \%)\end{array}$ & $94(100 \%)$ \\
\hline \multirow{4}{*}{$\frac{0}{\frac{\pi}{N}}$} & Left-Handed & $1(5.3 \%)$ & 0 & $2(4.3 \%)$ & $3(4.4 \%)$ \\
\hline & Ambidextrous & $2(10.5 \%)$ & 0 & $5(10.6 \%)$ & $7(10.3 \%)$ \\
\hline & Right-Handed & $16(84.2 \%)$ & $2(100 \%)$ & $40(85.1 \%)$ & $58(85.3 \%)$ \\
\hline & $\begin{array}{l}\text { Total (\% of Total } \\
\text { Males) }\end{array}$ & $\begin{array}{c}19 \\
(27.9 \%)\end{array}$ & $\begin{array}{c}2 \\
(2.9 \%)\end{array}$ & $\begin{array}{c}47 \\
(69.1 \%)\end{array}$ & $68(100 \%)$ \\
\hline
\end{tabular}

*\% is within the directional asymmetry subgroup 
Assessing for Gender Disparity in the Relationship between DA and EHI-GS Hand Preference Categories

In order to determine if there was gender disparity in the relationship between DA subgrouping and EHI-GS hand preference categories, we did cross-tabulation analysis and subjected the results to the Pearson Chi Square test of association (Table 3). The data revealed that overall, the pattern of DA with respect to EHI-GS hand preference categories was similar across the gender subgroups. The proportionate distribution by gender over the DA subgroups was similar: left DA (male $27.9 \%$, female $28.7 \%$ ), no DA (male $2.9 \%$, female $2.1 \%$ ), and right DA (male 69.1\%, female $69.1 \%$ ). This lack of a gender disparity in the relationship between DA and Hand preference was supported by the Pearson Chi Square Test of association (overall $\mathrm{X}_{2}=3.781$, $p=0.436)$, which gave female $X_{2}=5.197(p=$ $0.268 @ 95 \% \mathrm{CI})$ and Male $\mathrm{X}_{2}=0.388$ ( $\mathrm{p}=$ $0.983 @ 95 \% \mathrm{CI})$; both of which were not statistically significant. The results suggest that the proportionate distribution of subjects by gender in relation to DA and EHI-GS handedness was not statistically significant. This means that irrespective of the gender, EHI-GS handedness does not predict DA and purported DA will likewise not predict EHI-GS hand preference.
Relationship between directional asymmetry and hand efficiency by grip strength testing A cross-tabulation of results of the proportionate distribution of directional asymmetry subgroups with hand efficiency by grip strength testing was as shown in Table 4. Of the 63 subjects with left-sided hand dominance by grip strength testing, 18 (28.6\% of the left-sided hand dominant) showed DA in favour of the left side (ItDA) and 45 (71.4\% of the left-sided hand dominant) had a rightfavoured DA (rtDA). A total of 17 subjects had no-sided hand dominance by grip strength testing, with 4 (23.5\% of the no-sided hand dominant) showing left-favoured DA; 2 $(11.8 \%)$ showed no directional asymmetry (no DA) and 11 (64.7\% of the no-sided hand dominant) had DA favouring the right side (rtDA). Of the 82 subjects with right-sided hand dominance by grip strength testing, there were $24(29.3 \%$ of the right-sided hand dominant) with left-favoured DA (ItDA), 2 (2.4\% of the right-sided hand dominant) with no DA, and 56 (68.3\% of the right-sided hand dominant) with right-favoured DA (rtDA). The Pearson Chi Square test of association was used to evaluate the relationship between DA and hand efficiency by grip strength testing. This gave the total population $X_{2}=7.774(p=$ 0.100 @95\% CI), indicating a positive association between DA and hand efficiency by grip strength testing, although it was not statistically significant.

Table 4: Cross-tabulation of Directional Asymmetry Subgroups with Hand Efficiency by Grip Strength Testing

\begin{tabular}{|c|c|c|c|c|c|}
\hline \multirow{2}{*}{} & \multicolumn{2}{|c|}{ Directional Asymmetry Subgroup } & Total \\
\hline \multirow{4}{*}{$\begin{array}{c}\text { Grip } \\
\text { Strength } \\
\text { Hand } \\
\text { Dominance }\end{array}$} & Category & Left DA & None & Right DA & \\
\cline { 2 - 6 } & Left-sided & $18(39.1 \%)$ & 0 & $45(40.2 \%)$ & $63(38.9 \%)$ \\
\cline { 2 - 6 } & Right-sided & $24(52.2 \%)$ & $2(50.0 \%)$ & $56(50.0 \%)$ & $82(50.6 \%)$ \\
\cline { 2 - 6 } & $\begin{array}{c}\text { Total (\%) of } \\
\text { Total) }\end{array}$ & $\mathbf{4 6 ( 2 8 . 4 \% )}$ & $\mathbf{4 ( 2 . 5 \% )}$ & $\begin{array}{c}\mathbf{1 1 2} \\
\mathbf{( 6 9 . 1 \% )}\end{array}$ & $\begin{array}{c}\mathbf{1 6 2} \\
\mathbf{1 0 0 . 0 \% )}\end{array}$ \\
\hline
\end{tabular}

*\% is within the directional asymmetry subgroup 
Table 5: Cross-tabulation of Directional Asymmetry Subgroup with Hand Efficiency Categories by Grip Strength Testing Distributed by Gender

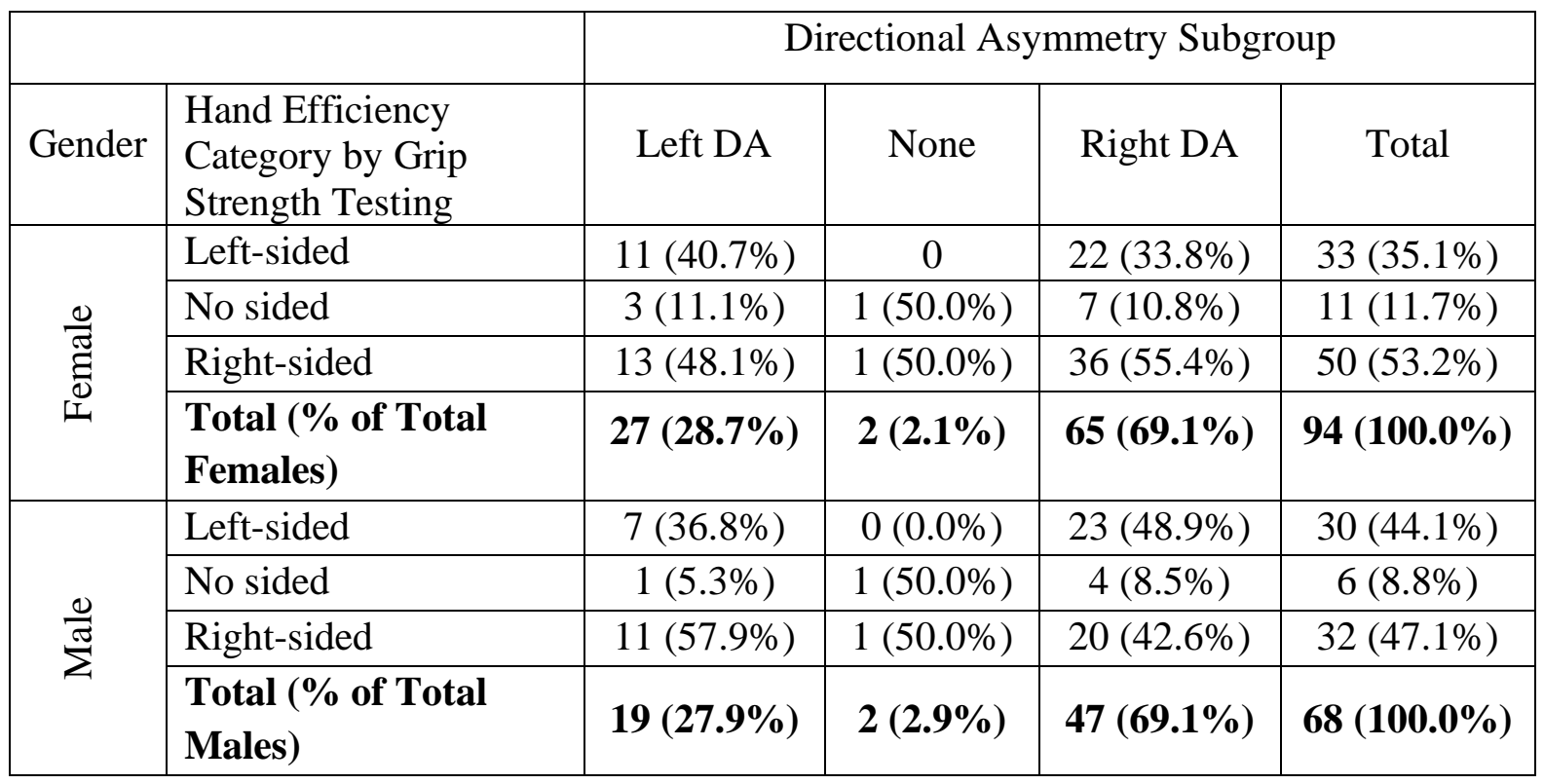

Assessing for Gender disparity in the relationship between $D A$ and hand efficiency by grip strength testing

Further analysis was done to asses for gender disparity in the relationship between DA subgrouping and hand efficiency by grip strength testing (Table 5). The pattern of DA with respect to hand efficiency by grip strength testing was similar across the gender subgroups. The proportionate distribution by gender over the DA subgroups in consideration of hand efficiency by grip strength testing was similar for males and females: left DA (male $27.9 \%$ vs female $28.7 \%$ ), no DA (male $2.9 \%$ vs female $2.1 \%$ ), and right DA (male $69.1 \%$ vs female $69.1 \%$ ).
There was lack of a gender disparity in the relationship between DA and Hand efficiency by grip strength testing, which was given credence by the Pearson Chi Square Test of association (overall $\mathrm{X}_{2}=7.774, \mathrm{p}=0.100$ ), which gave a female $X_{2}=3.731(p=0.444$ $@ 95 \%$ CI $)$ and Male $X_{2}=6.159(p=0.188$ @ $95 \% \mathrm{CI}$ ); both of which were not statistically significant. These results suggest that the proportionate distribution of subjects by gender in relation to DA and hand efficiency by grip strength testing was also not statistically significant. This means that, notwithstanding gender, hand efficiency by grip strength testing does not predict DA, neither can DA predict hand efficiency by grip strength testing.

\section{DISCUSSION}

Hand asymmetry seems like a phenomenon that should be expected in the population despite records indicating that these asymmetries are often very small and subtle. In their study, Barut et al. (2011) detected statistically significant differences between right and left hands for the handedness subgroups in measurements of hand width, shape index, and palmar length/width value $(p<0.001)$. In the current study, statistically significant asymmetries with similar $\mathrm{p}$-values were recorded in measurements of hand width, palm breadth, index finger width, ring finger width, and the calculated hand volume.

Another study by Kumar et al. (2015) reported displays of irregular and heterogeneous characteristics of hand parameters amongst left-hand preference groups, while ambidextrous subjects did not show significant differences in the hand parameter values with either right or hands. The current study 
certainly confirmed the small and subtle differences between the right and left hands as previously detected (Barut et al., 2011), and therefore as much expected. It further indicated that this did happen across all the parameters which were measured even if some were not statistically significant. The supported theory is that such information can be useful in cases of hand fitting gloves and work environment fittings for railings and door handles.

In another study, Buffa et al. (2007) analysed forms of disparity of the human hand, and studied in particular, the standards of measurements of features of the palm, fingers and distal phalanges. These researchers assessed lengths of the palm and fingers in respect of gender and hand preference and reasoned that there is apparent sexual dimorphism because men generally have greater hand dimensions and relatively more thumb development. Likewise, the current study showed statistically significant differences in the measurements that gave a gender disparity in DA. In both studies, the morphological variation and laterality demonstrated by DA showed the males to generally have larger hand measures with statistically significant differences compared with the female hand measures. It is noteworthy that Subira and Malgosa (1988) had also reported higher measurement results of hand width and length amongst male subjects.

In their study, Kulaksiz and Gozil (2002) rationalized that the larger dimensions of hand width, hand length and 3rd digit length reported as higher in males should explain the observed coarser and wider masculine hands as compared to the more delicate and narrower feminine hands. Other research findings argued that the greater right-hand width could be because of more use of the right hand by the subjects (Annett, 1970; Ellis et al., 1988; Tan, 1988 and 1993), which then turns out to be wider (Subira and Malgosa, 1988). In concordance with other studies such as Laubach and McConville (1967), the current study population reveals the right hand to be noticeably wider compared to the left. On their part, Kumar et al (2015) also reported hand breadth that was considerably bigger on the right compared to the left side and indicated that right-handed individuals have broader right than left hands. It is key to remember that finding statistically significant differences in anthropometric dimensions does not necessarily translate into practical significance.

However, as noted in the present study, scrutiny of the resultant DA with reference to hand efficiency and handedness did not show gender disparity. As Kumar et al. (2015) muse, the preferred hand inevitably has a potent influence on hand length, hand breadth, and shape index; but consideration must be made to environmental and genetic factors as well as structural asymmetry which may play a part in the determination of that potency. This may be the reason why there are some observed irregular characteristics such as right-handed individuals presenting with left-favoured DA (ItDA); or left-sided hand efficiency being associated with right-favoured DA (rtDA); or even the very rare ambidextrous combining with no DA. The point here is that when different tests of the hand are analysed separately, they show a gender disparity. However, when the tests are analysed in combination, the relationships seem to be similar between males and females.

In conclusion, hand anthropometric measurements in this study population showed a general right-favoured asymmetry (rDA), with a corresponding highly positive correlation across all measured parameters between the left and right hands. This accounts for the similarity that is immediately apparent when one makes a quick glance at the morphology of the human hands. Of note is finding that the established DA did not predict either hand preference or hand efficiency. Likewise, neither hand preference by EHI-GS nor hand efficiency by grip strength testing predicted DA in either males or females. 
Anatomy Journal of Africa. 2020. Vol 9 (2): 1848-1856.

\section{REFERENCES}

1. Annett M. 1970. A classification of hand preference by association analysis. Br J Psychol. 61:303-321 https://doi.org/10.1111/j.2044-8295.1970.tb01248.x

2. Barut C, Demirel P, Kiran S. 2008. Evaluation of hand anthropometric measurements and grip strength in basketball,volleyball and handball players. Anatomy. 2:55-59. doi:10.2399/ana.08.055

3. Barut C, Sevinc O, Sumbuloglu V. 2011. Evaluation of hand asymmetry in relation to hand preference. Coll Antropol. 35:1119-24.

4. Buffa R, Marini E, Cabras S, Scalas G \& Floris G. 2007. Patterns of Hand Variation - New Data on a Sardinian Sample. Coll Antropol. 31(1):315-319.

5. Cavala M, Rogulj N, Srhoj V, Srhoj L, Katić R. 2008. Biomotor structures in elite female handball players according to performance. Coll Antropol. 32(1):231-239.

6. Ellis SJ, Ellis PJ, Marshall E. 1988. Hand preference in a normal population. Cortex 24:157-163 https://doi.org/10.1016/S0010-9452(88)80025-X

7. Jones HH, Priest JD, Hayes WC, Tichenor CC, Nagel DA. 1977. Humeral hypertrophy in response to exercise. J Bone Joint Surg 59(2):204-208.

8. Kontulainen S, Kannus $P$, Haapasalo $H$, Sievänen $H$, Pasanen M, Heinonen A, et al. 2001. Good maintenance of exercise-induced bone gain with decreased training of female tennis and squash players: a prospective 5-year follow-up study of young and old starters and controls. $J$ Bone Miner Res. 16(2):195-201. doi:10.1359/jbmr.2001.16.2.195

9. Kontulainen S, Sievänen H, Kannus P, Pasanen M, Vuori, I. 2002. Effect of long-term impact-loading on mass, size, and estimated strength of humerus and radius of female racquet-sports players: a peripheral quantitative computed tomography study between young and old starters and controls. $J$ Bone Miner Res. 17(12):2281-2289. doi:10.1359/jbmr.2002.17.12.2281

10. Kulaksiz G. and Gozil R. 2002. The effect of hand preference on hand anthropometric measurements in healthy individuals. Ann of Anat. 184:257-65. doi:10.1016/s0940-9602(02)80119-4

11. Kumar T, Singh V, Mattoo MK, Gimire SS. 2015. Effect Of Hand Preference On Hand Length, Hand Breadth and Shape Indices and Its Role in Sexual Dimorphism: A Study in 300 Kashmiri Pandits. IOSR JDMS. Pp. 10-16. DOI: 10.9790/0853-14371016

12. Laubach LL. and McConville JT. 1967. Notes on anthropometric technique: Anthropometric measurements - right and left sides. Am. J. Phys. Anthropol. 26(3):367-369. doi:10.1002/ajpa.1330260314

13. Lazenby RA, Cooper DML, Angus S, Hallgrimsson B. 2008. Articular constraint, handedness, and directional asymmetry in the human second metacarpal. J. Hum. Evol. 54(6):875-85. doi: 10.1016/j.jhevol.2007.12.001

14. Malina RM. and Buschang PH. 1984. Anthropometric asymmetry in normal and mentally retarded males. Ann Hum Biol. 11(6):515-531. doi:10.1080/03014468400007431

15. Mayor GH, Garn SM, Sanchez TV, Shaw HA. 1976. Proceedings: The need for differential bone mineral standards for blacks. AJR Am J Roentgenol. 126:1293-1297. doi:10.2214/ajr.126.6.1293

16. Oldfield RC. 1971. The assessment and analysis of handedness: The Edinburgh inventory. Neuropsychologia. 9(1):97-113. doi: 10.1016/0028-3932(71)90067-4

17. Pheasent S. 1990. Anthropometrics: An Introduction. United Kingdom: British Standards Institution; p. $18-9$

18. Srhoj V, Marinović M, and Rogulj N. 2002. Position specific morphological characteristics of top-level male handball players. Coll Antropol. 26(1):219-227.

19. Steele J. 2000. Skeletal indicators of handedness. In: Cox, M and Mays, S, (eds.) Human Osteology. London: Greenwich Medical Media; pp. 307-323.

20. Subira ME and Malgosa A. 1988. Somatometric study of the hands. Int J Anthropol. 3:329-338

21. Tan U. 1988. The distribution of hand preference in normal men and women. Int. J. Neurosci. 41(12): 35-55 doi: $10.3109 / 00207458808985740$

22. Tan U. 1993. Normal distribution of hand preference and its bimodality. Int. J. Neurosci. 68:61-68 https://doi.org/10.3109/00207459308994260

23. Tomkinson GR, Popović N, and Martin M. 2003. Bilateral symmetry and the competitive standard attained in elite and sub-elite sport. J. Sports Sci. 21(3):201-211. doi:10.1080/0264041031000071029a. 